\title{
Analysis of Current Production Status and Key Existing Problems of Tower-Shaped Solar Molten Salt Storage Tank
}

\author{
Hang XI, Qiong WU1', Xiaojun XIE, Ruigang ZHANG, Bo YANG, Qian LIU \\ $X i$ 'an Thermal Power Research Institute Co., Ltd., Xi'an 710054, China
}

\begin{abstract}
In this paper, the development and prospect of tower-shaped solar thermal power generation technology are briefly introduced, and the importance of production quality of molten salt storage tank in tower thermal power storage system is proposed. The production technology and construction process of molten salt storage tank are described in detail, and the key technology and multiple problems affecting quality are analysed. Aiming at the problem of fillet weld deformation, this paper proposes a new anti-deformation tooling and welding operation technology. At last, this paper presents a construction technology method and a solution to improve the welding quality of molten salt storage tank, which can effectively solve the problem that the bottom plate of molten salt storage tank is out of standard due to welding.
\end{abstract}

Keywords. tower-shaped solar thermal power generation, construction technology method, salt storage tank

\section{Introduction}

On September 13, 2016, the National Energy Administration issued 'the Notice on the Construction of Solar Thermal Power Generation Demonstration Projects' (Guoneng Xinneng [2016] No. 223) document, comfirmed that the first batch of solar thermal power generation demonstration projects totalled 20, with a total installed capacity of 1.349 million kilowatts. They are distributed in Qinghai Province, Gansu Province, Hebei Province, Inner Mongolia Autonomous Region and Xinjiang Autonomous Region [1]. At present, the domestic construction projects include Dunhuang 100MW molten salt tower solar thermal power generation project, Delingha 50MW molten salt solar thermal power generation project, Hami 50MW molten salt solar thermal power generation project, Qinghai Gonghe 50MW molten salt solar thermal power generation project. Most tower-shaped solar thermal power generation projects are in the experimental stage, and the operating experience is still being explored and improved. To vigorously develop non-fossil energy and gradually replace fossil energy is the primary energy development strategy to ensure China's energy security, achieving sustainable economic development, and reduce pollutants and greenhouse gas emissions [2-3]. The solar radiation is concentrated on a heat absorber installed on a tower of a certain height through heliostats, to collect the heat energy, and steam is generated to

${ }^{1}$ Corresponding author: Qiong Wu, Xi'an Thermal Power Research Institute Co., Ltd., Xi'an 710054, China; E-mail: wuqiong.0702@163.com. 
drive the steam turbine to generate electricity. This method is the solar tower thermal power generation technology. Tower molten salt solar thermal power station is mainly composed of five parts: concentrating system, heat absorption system, heat storage system, steam generation system, and power generation system. The heat storage system is particularly important because the stability of the system is the key link unit of continuous power generation that can be achieved by solar thermal power generation. A delicate design for molten salt volume and wall thickness of tanks in the thermal storage system of CSP plants has been presented in [4]. The strategy can relieve the thermal stress during storage tank preheating and reduce its risk and failure rate. In [5] mainly analyzes the technology and system structure of solar thermal power generation, points out the existing problems and solutions of solar thermal power generation equipment. In [6] presented a method of optimizing the molten salt consumption which can significantly reduce the consumption of molten salt. At present, domestic and foreign countries pay more attention to the production quality and manufacturing process of the equipment in the heat storage system, and even some owners will hire an equipment supervision company to control the heat storage system-manufacturing quality strictly to eliminate hidden production quality problems. In 2016, the Xinyue sandbank power station, the world's largest installed molten salt tower power station, experienced a small-scale molten salt tank leakage accident, which caused the power station to be directly offline and out of service, excluding the planned maintenance period as described by SolarReserve. The power station was unable to generate electricity for at least two months due to the accident. Compared with the economic loss caused by repairing the thermal storage tank, the greater loss lies in the loss of electricity sales revenue caused by the shutdown of the power station. According to the statistics at that time, the monthly generating capacity of the power station reached 30514MWh in September of that year, and the PPA contract price of the project was $\$ 0.135 / \mathrm{kWh}$. According to this rough estimate, the loss of electricity sales revenue caused by the one-month shutdown was about $\$ 4$ million. It can be seen that if the quality problem of molten salt storage tank in the heat storage system is ignored, it will bring significant impact and huge loss to the operating enterprises [7].

\section{Introduction to the Production Technology of Molten Salt Storage Tank}

Generally, there are 1 low temperature molten salt storage tank (abbreviated as " low temperature tank") and 1 high temperature molten salt storage tank (abbreviated as "high temperature tank") in the molten salt storage tank of tower solar thermal power generation project. One low temperature tank is used for storing molten salt with a temperature below $400^{\circ} \mathrm{C}$, and one independent high temperature tank is used for storing molten salt with a temperature above $400^{\circ} \mathrm{C}$. The liquid level of the molten salt storage tank will rise or fall with the operation of the heat absorber and steam turbine unit every day. The design of the molten salt storage tank is suitable for the circulating mode of liquid level operation and the thermal stress changes. Molten salt heat storage medium is adopted in the generator set. The heat storage medium is NaNO3, KNO3 binary molten salt and the molten salt heat storage system is equipped [8]. 


\subsection{Molten Salt Storage Tank Manufacturing and Installation Welding}

The molten salt storage tank can be divided into three parts: tank bottom, tank wall and tank top. The main manufacturing process contains ten parts which is shown in Figure 1:

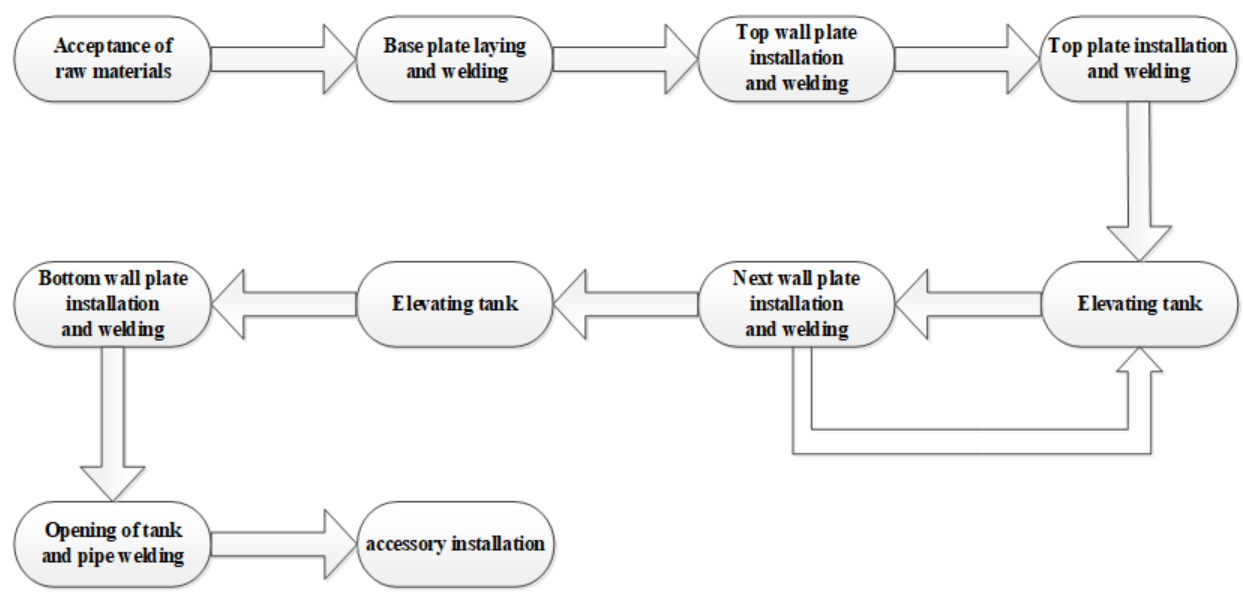

Figure 1. Flowchart of molten salt storage tank manufacturing process.

At present, the main construction parameters of the tower molten salt storage tank are shown in Table 1:

Table 1. Construction parameters of tower type molten salt storage tank.

\begin{tabular}{ccc}
\hline Project & Interval & Angle \\
Edge plate joint & $\begin{array}{c}\text { Inner } 12 \sim 14 \mathrm{~mm} ; \\
\text { outer } 8 \sim 10 \mathrm{~mm}\end{array}$ & $55^{\circ}$ \\
Shrinkage joint of middle & $6 \mathrm{~mm}$ & $60^{\circ}$ \\
plate butt joint & & \\
Large Angle seam & $2 \sim 3 \mathrm{~mm}$ & Inside and outside $50^{\circ}$ \\
Circumferential weld of tank wall & $1 \pm 1 \mathrm{~mm}$ & outside $60^{\circ}$ \\
Vertical weld of tank wall & $2 \mathrm{~mm}$ & $55^{\circ}$ \\
\hline
\end{tabular}

Based on the current domestic construction technology, bottom plate welding is divided into edge plate welding and medium plate welding. The welding of the medium plate is formed by argon arc welding, manual welding with welding rod and manual welding to fill the cover surface. When laying the middle plate, it shall be laid from the center to the periphery according to the layout drawing, and the edge plate shall be laid according to the installation position line. The welding shall be carried out in the order of first short and then long. The primary seam bead shall be welded by subsection back 
welding method. When welding the middle plate of tank bottom plate, it shall be carried out in the order as shown in Figure 2:

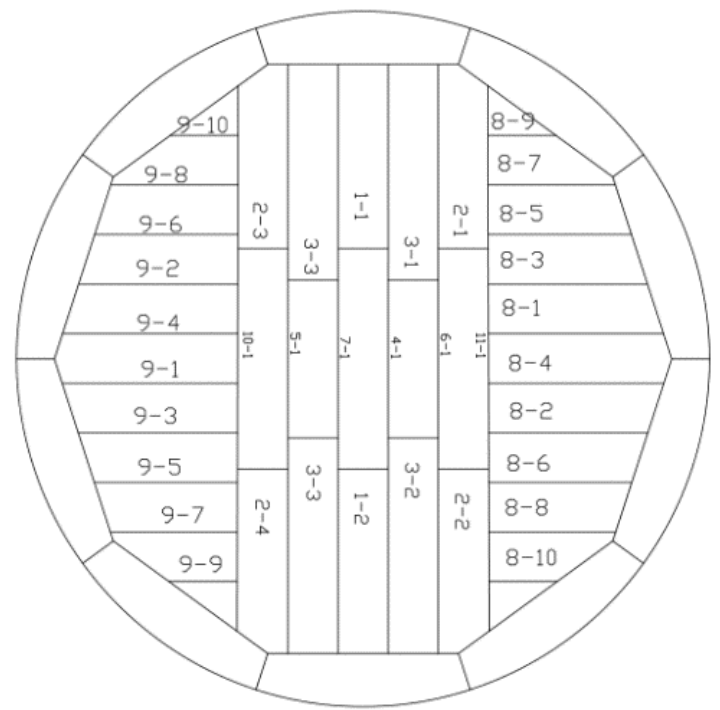

Figure 2. Welding number drawing of tank bottom plate.

Follow the welding sequence and direction shown in the figure above to perform segmented reverse jump welding. The welds in the same group shall be welded at the same time, with the same segment length, the same number of welding layers, the same welding current and welding speed, and the welding joints between layers shall be staggered. In addition, the T-mouth area of $200 \mathrm{~mm}$ between the middle plate shall be reserved for welding, which shall be completed by manual welding after the completion of long and short seam welding. When welding tank bottom plate, anti-deformation measures should be taken. When welding short seam, the back plate should be made at both ends of the weld $150 \mathrm{~mm}$ away from the edge (the length of the back plate is not less than $600 \mathrm{~mm}$, the width of the back plate is not less than $150 \mathrm{~mm}$ ). When welding long joints use a gantry plate to fix the No. 20 channel steel on both sides of the weld, $200 \mathrm{~mm}$ away from the weld and clamp it tightly.

The flip-flop method is adopted to install the wall of the molten salt storage tank, that is, the top ring wall and the vault are installed first, then the wall is installed and welded downward in turn, and finally the bottom ring wall and the large fillet weld are installed. According to this installation method, the vertical and circular joints of the panel are welded by argon arc, and then a temporary operating platform is set up inside for root cleaning and welding. The inner and outer sides of the vertical seam are welded by argon electric joint. The outer side of the ring seam is welded by argon electric joint and manual arc welding. The inner side is welded by manual arc welding.

After the top ring panel group is finished, longitudinal seam welding is carried out first. The welding method uses argon electric vertical welding, welding the big groove first, then welding the small groove, and then using the inner operating platform to clean the weld root. Root cleaning can be done by grinder, but the carburizing layer and debris in the planer groove are polished clean by angular grinder.

After the $300 \mathrm{~mm}$ welding of the outer edge of the bottom ring panel and the bottom plate edge plate is completed, the large fillet weld shall be welded. Arc welding is used 
for welding, and the groove is fully penetrated. Therefore, it is necessary to pay attention to prevent large welding deformation due to stress release during welding, which will affect the product quality of molten salt storage tank.

\subsection{Welding Method for Various Parts of High and Low Temperature Molten Salt Storage Tank}

Because the core work of molten salt tank manufacturing is welding steel material, the welding method and welding material requirements for the welding process of steel materials are particularly important. The main welding methods and characteristics, one is electrode arc welding (SMAW) method, which is characterized by flexible process, strong adaptability, small heat affected zone, simple equipment, easy operation, but poor working conditions, low productivity. The second method is gas metal arc welding (GMAW), which is characterized by high productivity, easy to realize the automation of welding process, flexible operation, but poor wind resistance. The third is to choose submerged arc welding (SAW), which is characterized by high production efficiency and good working conditions, but complex equipment, easy to oxidize metal is difficult to be welded, welding parts are easy to be limited by space position. Fourth, gas shielded tungsten arc welding (GTAW) is characterized by stable arc, high welding quality, easy all-position welding and a wide range of welding materials, but with poor wind resistance and low efficiency [9-10]. SMAW, GMAW, SAW, GTAW are adopted for the steel materials of molten salt storage tanks. During process welding, the temperature between layers should be controlled below $100^{\circ} \mathrm{C}$. The specific welding methods and welding materials are shown in Table 2 and 3.

Table 2. Welding method and welding material for low temperature molten salt storage tank.

\begin{tabular}{cccc}
\hline Number & Welding parts & Welding method & Welding materials \\
\hline 1 & Bottom plate & GTAW+SMAW & E5015(J507) \\
2 & Vertical joints on the wall & GTAW+SAW & E5015(J507) \\
3 & Circular joints on the wall & GTAW+SMAW & welding stick/J507 \\
4 & Big fillet weld & GMAW+SMAW & J507+H10Mn2 \\
5 & Vault of tank & SMAW & J507 \\
\hline
\end{tabular}

Table 3. Welding method and welding material for high temperature molten salt storage tank.

\begin{tabular}{cccc}
\hline Number & Welding parts & Welding method & Welding materials \\
\hline 1 & Bottom plate & GTAW+SMAW & E347-16 \\
& & & \\
2 & Vertical joints on & GTAW+SAW & E347-16 \\
& the wall & & \\
3 & Circular joints on & GTAW+SMAW+ & welding stick \\
& the wall & SAW & /E347-16 \\
4 & Big fillet weld & GMAW+SMAW & E347-16 \\
5 & Vault of tank & SMAW & E347-16 \\
\hline
\end{tabular}




\section{Analysis of Key Technology and Multiple Problems in Molten Salt Storage Tank Production}

\subsection{Key Welding Process}

In the production welding of molten salt storage tank, the fillet welding technology between the bottom plate of high temperature tank and the bottom ring wall plate is particularly important. Due to the large difference between the bottom ring wall thickness and the bottom plate edge thickness, and the groove is full penetration, the fillet weld deformation is also obvious in the welding process. In order to prevent large welding deformation, corresponding measures need to be taken in the welding process. The inner side of the wall plate and the edge plate of the bottom plate should be made of steel pipe, and the stainless steel plate should be welded on both sides of the steel pipe for isolation. The outer side of the wall plate and the edge plate of the bottom plate should be made of stainless steel plate for oblique support, so as to effectively prevent the phenomenon of the edge plate of the bottom plate and the bottom plate from bulging. Welding anti-deformation tooling is shown in Figure 3.

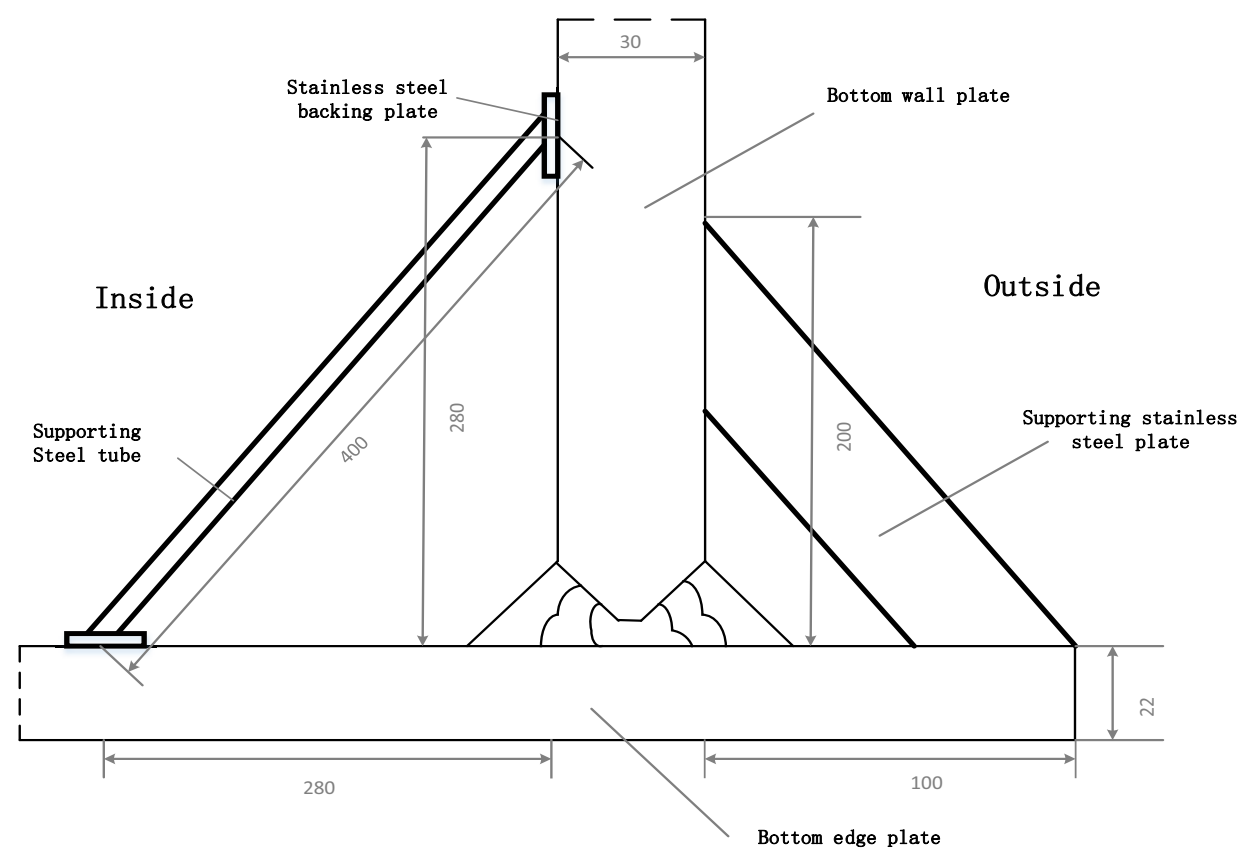

Lateral view 


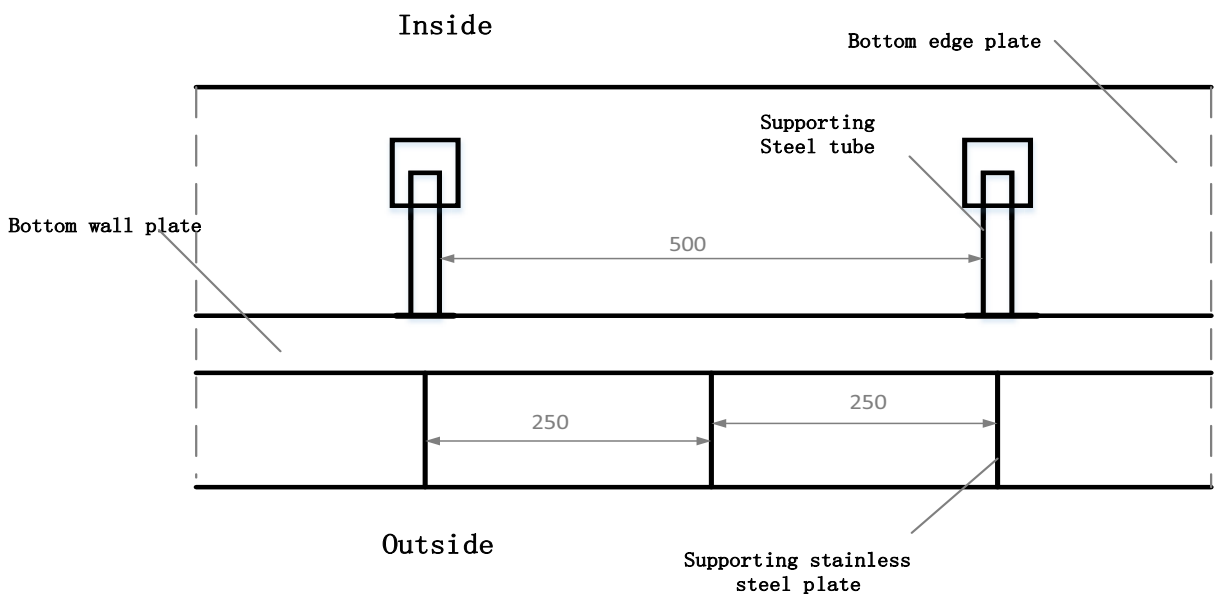

Vertical view

Figure 3. Welding anti-deformation tooling drawing.

Spot welding between the bottom plate edge plate and the backing plate, and the spot welding weld should be as long as possible to prevent the right side of the bottom plate edge plate from warping. At the same time, the heat input, inter-layer temperature and welding sequence should be well controlled during welding. And the local climate temperature should be taken into account when welding the fillet weld, and the welding operation should be carried out in the high-temperature period as far as possible.

The welding personnel should be distributed symmetrically in the circumferental direction of the large fillet weld, and perform welding along the same welding direction at the same time; The welding is separately backwelded in the same direction from the inside and outside of the tank. The inner and outer fillet welds are welded alternately. The inner fillet welds are welded first, and then the outer fillet welds are welded. When welding, the beginning end shall adopt the backward arc method, and the end shall fill the arc pit. Multi-layer and multi-pass welding shall be used for inter-layer welding. The indirect ends of the layers shall be staggered at least $50 \mathrm{~mm}$, and the welding speed, welding angle and welding current shall be consistent. The specific welding work should be carried out by welding electrode arc welding from the inside of the tank. The bottom is carried out by welding electrode with small current, fast speed and no swing. The inner side is welded for three layers, and the back side is cleaned, polished and cleaned, and then the penetration detection is carried out. The next procedure can be welded after passing the inspection and detection.

In-process penetration testing shall be carried out after the welding of the primary layer of the large fillet weld between the bottom plate and the wall plate. Permeability inspection shall be carried out on the inside and outside of the fillet welds after all welding. If there are any defects, corresponding schemes shall be formulated to eliminate them. After the tank flushing test is completed, the fillet weld shall be re-inspected in the same manner. It should be noted that the solder joint shall be polished smoothly after the removal of the anti-deformation tooling, and the tank shall be avoided from damage during the removal process. 


\subsection{Multiple Problems and Treatment in the Welding Process of Storage Tank}

After the circular weld welding between the bottom plate edge plate and the middle plate and after the welding of the bottom plate and the wall edge plate is completed.The welding stress is too large to cause the local deformation of the bottom plate and out of tolerance, due to the improper process control in the welding process or the large temperature difference between day and night in the welding environment, which is difficult to control the welding temperature between layers. Serious floor deformation will not meet the requirements of 7.3.2 of GB 50128-2014. Therefore, reasonable rectification measures and effective rectification schemes are put forward to better control the production quality of products.

Firstly, a pressure plate is used to shape the large part of the local deformation of the edge plate of the bottom plate, so that the welding stress is dispersed. By increasing the upper load of the bottom plate, the welding stress is gradually eliminated with time and the increase of the upper load, and the local deformation of the edge plate of the bottom plate is further solved.

After the floor fabrication tooling is completely dismantled, Hawker energy dissipation method can be used to eliminate stress, so that the deformation caused by the floor stress concentration can be controlled within the allowable range of the drawings or standards. The basic principle of Hawker welding stress relief technology is that the fusion welding method is generally adopted in the welding of metal structural parts. In the filling process of metal, excess height, pits and various welding defects are left in the joint parts, resulting in serious stress concentration and a certain amount of welding residual stress. In most cases, residual tensile stress is bad for the fatigue strength of welded structures. So after welding using Hawker energy promote impact tools more than twenty thousand times per second frequency along the direction of the weld position of the weld toe, to produce larger compression deformation, make the weld toe area produces smooth geometry transition, greatly reduces the toe place more than high and depressions caused by stress concentration, adjust the welding residual stress field, eliminate the welding stress. A certain amount of residual compressive stress is generated near the toe, and the material at the toe can be strengthened. Using Hawker energy dissipation method can simultaneously improve several factors affecting the fatigue performance of welds, such as weld toe geometry, residual stress, micro cracks and slag, surface strengthening and other defects. Therefore, this method can greatly improve the fatigue strength and fatigue life of the welded joint, eliminate the welding residual stress, reduce the welding deformation, etc., and can effectively solve the problem that the bottom plate deformation is out of tolerance due to the welding residual stress is not eliminated.

\section{Conclusion}

To sum up, this paper puts forward the importance of welding quality in molten salt tank manufacturing because the quality problem of molten salt storage tank causes the influence of power generation. Then, the production process and production technology requirements of molten salt storage tanks are introduced in detail. Finally, by analyzing typical quality problems and key process content, this paper proposes the use of increased anti-deformation tooling and Hawker energy dissipation methods to solve the problem of excessive welding stress caused by local deformation of the edge plate of the 
bottom plate, while avoiding storage quality defects caused by improper tank welding and other reasons. At present, tower power stations are not mature enough in key technologies, which still need continuous development and exploration. The cost of power generation is also expensive, and a complete and mature system of design, construction, operation and maintenance has not been formed. The problem solution and welding process measures proposed in this paper also hope to play a certain guiding role in the subsequent production work of solar thermal storage tank.

\section{Acknowledgements}

This paper was supported by the "Wind-photovoltaic-water coordinating optimization technology research" of science and technology project of Huaneng Group Headquarters (HNKJ18-H35).

\section{References}

[1] Solar Thermal Alliance, Operation record of three solar thermal power stations put into operation in China [EB/OL]. https://solar.in-en.com/html/solar-2342724.shtml,2019-06-19.

[2] Wang P. Study on design technology of molten salt storage tank for solar thermal power generation. Qinghai Electric Power, 2018, 37(3): 37-40 (in Chinese).

[3] Gao XX. Structure design and performance study of molten salt tank [D]. Xian: Northwest University, 2018 (in Chinese).

[4] Han W, Cui KP, Zhao XH, Francisco M. Design for CSP plants' energy storage system and research on preheating strategy with tanks. Huandian Technology, 2020, 42(4): 1674-1951 (in Chinese).

[5] Li HW. Research on the current situation of solar thermal power generation technology and the existing problems of key equipment. Electronic Test, 2020(01):131-132 (in Chinese).

[6] Sun YH. Design optimization of molten salt quantity in thermal storage system of concentrated solar power plant and its engineering applicatio. Construction \& Design for Engineering, 2020, (22):101-103 (in Chinese).

[7] CSPPLAZA. Analysis of seven causes of molten salt leakage accident in Xinyue sandbank Power Station [EB/OL]. http://guangfu.bjx.com.cn/news/20161207/794644.shtml, 2016-12-07.

[8] Yuan F, Li MJ, Ma Z, et al. Experimental study on thermal performance of high-temperature molten salt cascaded latent heat thermal energy storage system. International Journal of Heat and Mass Transfer, 2018 (118):997-1011 (in Chinese).

[9] Wang YS,Chu TQ,Wang Z, et al. Experimental study on heat dissipation of molten salt heat storage tank. Journal of Shenyang Institute of Engineering:Natural Science, 2019,15(1):54-58 (in Chinese).

[10]Yue S, Li M. Solar thermal power energy storage technology and system analysis. Applied Energy Technology, 2019(7):54-56 (in Chinese). 